\title{
Parent-Adolescent Communication on Sexual and Reproductive Health Issues and Associated Factors Among Secondary and Preparatory School Students in Agaro town, Jimma Zone Southwest Ethiopia
}

Daba Abdissa ( $\nabla$ dhaabaa4@gmail.com )

Jimma University https://orcid.org/0000-0002-2979-7450

Workitu Sileshi

Jimma University

Research

Keywords: Communication, sexual and reproductive health, Adolescent, Parent, Ethiopia

Posted Date: January 8th, 2021

DOI: https://doi.org/10.21203/rs.3.rs-140401/v1

License: (c) (i) This work is licensed under a Creative Commons Attribution 4.0 International License. Read Full License 


\section{Abstract}

Background: Adolescents are rarely provided with adequate information about their development, especially in regard to sexuality. This problem has exposed the adolescents to the risk of many sexual and reproductive health problems. Parents have significant role to reduce sexual risk behaviors and promote healthy adolescent sexual development. Hence, the aim of this study was to assess parent-adolescent communication on SRH issues among secondary and preparatory school students in Agaro town, Southwest Ethiopia, 2019.

Methods: School based cross-sectional study was conducted from April 13-20/2019 using stratified random sampling technique. Data were collected using pretested interviewer-administered structured questionnaire entered into Epi data version 3.1; and analyzed using SPSS version 20. A variable having a p-value of $<0.25$ in the bivariable model was subjected to multivariable analysis to avoid the confounding variable's effect. Adjusted odds ratios were calculated at the 95\% confidence interval and considered significant with a $p$-value of $<0.05$.

Results: A total of 315 students were included to the study. The mean age of the respondents was $20.2 \pm 2.6$ years. The study finding showed that $61.3 \%$ of the participants were discussed on SRH issues with their parents. Educational status of mother [primary education ( $A O R=3.67 ; 95 \% \mathrm{Cl}: 1.93,6.97)$, secondary education(AOR:2.86;95\% Cl:1.2,6.8)], educational status of father[primary education ( $A O R=5.8 ; 95 \% \mathrm{Cl}: 2.8,12.3$, secondary education ( $A O R=3.21 ; 95 \% \mathrm{Cl}: 1.55,6.59)$ ], having family size of $<5(A O R=6.4 ; 95 \% \mathrm{Cl}: 3.36,12.37)$ and having boy/girlfriend(AOR=1.99; 95\% Cl:1,3.8) were significantly associated with parent adolescent communication.

Conclusion: About two third of the participants communicate with their parents. parents' educational status, family size of $<5$ and having boy/girlfriend were significantly associated with the communication.

\section{Plain English Summary}

Adolescents are rarely provided with adequate information about their development, especially in regard to sexuality. This problem has exposed the adolescents to the risk of many sexual and reproductive health problems. Parents have significant role to reduce sexual risk behaviors and promote healthy adolescent sexual development. This study was aimed to assess parent-adolescent communication on SRH issues among secondary and preparatory school students. using pretested interviewer-administered structured questionnaire.

A total of 315 students were included to the study. The study finding showed that $61.3 \%$ of the participants were discussed on SRH issues with their parents. Educational status of mother, educational status of father, having family size of $<5$ and having boy/girlfriend were significantly associated with parent adolescent communication.

In conclusion, about two third of the participants communicate with their parents. parents' educational status, family size of $<5$ and having boy/girlfriend were significantly associated with the communication.

\section{Introduction}

Adolescence is the period of transition from childhood to adulthood characterized by significant physical, cognitive, social and emotional changes. Because of the rapid cognitive, physical and emotional developments that takes place before adequate information, skills and experience of life is achieved, adolescence is a time when several health problems emerge unless managed properly $(1,2)$.

Globally, a significant number of adolescents and youth aged 10 to 24 years die each year due to lack of information about available health services and avoidable sexual and reproductive health (SRH) negative consequences. Each year around the globe sixteen million late adolescent girls give birth, in which 95 percent of them occur in developing countries(3). Unplanned birth for unmarried adolescent women results in dropout of school, rejection from family and community. Besides, 
adolescents present with a highest incidence rate for sexually transmitted infections (4). The main cause for the above situation is the gap in promoting the SRH agenda and adolescent health is usually ignored area in health priority (5).

Parent-adolescent communication on $\mathrm{SRH}$ issues with adolescents is vital in reducing risky sexual behaviors and negative its consequences (6). It is fundamental process through which parents transmit sexual values, information, beliefs, and expectations to their children with the purpose of influencing sexual behaviours, attitudes and decision-making of their children and becomes effective when parents are openly discussed, skilled, and comfortable in their discussion of sex related topics (7). Parents are the primary source of information concerning sexuality and adolescents prefer to receive sexual information from their parents (8).

Studies revealed that adolescents in Ethiopia have very low health-seeking behavior mainly to their SRH matters and even the current reproductive health services are not adolescent-centered $(9,10)$. Even though the Ethiopian government has identified the reproductive health of adolescents as one of the priority areas in the national reproductive health strategy, it is not yet put in practice(11). Furthermore, the government of Ethiopia has set objectives with strategies that encourage parents' participation, but little is known about the parental engagement (12). In general, to decrease adolescent's morbidity and mortality, parent-adolescent communication about SRH issues were crucial and can greatly reduce adolescent's sexual risk.

Parent-adolescent communication on SRH issues in Ethiopia is believed to be socially disgraceful (13) and most youthfriendly services and health care providers in Ethiopia are not well prepared in addressing adolescents' SRH desires. As a result, most of the adolescent communication attempts regarding sexual matters is generally misguided by their peer group of the same sex and many teenagers do not have access to reliable information regarding their SRH needs $(9,14)$. Hence, the participation of community members, families, and other stakeholders is important to improve the health status of the adolescents. As adolescents are cornerstone for future economic development, policy and strategy that support adolescent should be develop to reduce the risk of adolescent health problem.

The factors associated with the communication are parental education, adolescent's age and living arrangements, type of parents, and parents' sexual and reproductive health knowledge and attitude $(13,15,16)$.

In Ethiopia limited study was conducted on parents-adolescents communication on sexual and reproductive health and to our knowledge, there is no established evidence regarding the prevalence and associated factors of parent adolescent communication on SRH in Agaro town, Oromia region Ethiopia. Hence, this study was aimed at assessing the prevalence and associated factors of parent adolescent communication on SRH among secondary and preparatory school students for risk minimization and better health. This study will help to provide information regarding the prevalence of parent adolescent communication on SRH and its determinants to suggest possible ways of improving the challenges in family communication. Moreover, this study will attempt to generate evidence based information for concerned government bodies and policy makers to consider the situation and to design an appropriate intervention strategy.

\section{Methods}

\subsection{Study area, period and design}

School-based cross-sectional study was conducted among secondary and preparatory school students at Agaro town, Jimma Zone, Southwest Ethiopia from April 13-20/2019. It is located $45 \mathrm{~km}$ from Jimma town and $391 \mathrm{~km}$ from Addis Ababa. There are educational services from kindergarten to university in the town and it has two health centers and one primary hospital. There are 2 secondary and preparatory schools and 4 secondary schools in the town. According to the data obtained from school directors, the schools had 2818 total regular secondary and preparatory students during the study period.

\subsection{Population}


The source population comprised of all Agaro secondary and preparatory school students during the academic year of 2019, while the study population comprised all Agaro secondary and preparatory school students who fulfilled the inclusion criteria.

\section{Eligibility criteria}

Regular students were included in the study, whereas students absent from class on data collection days, sick and married students were excluded.

\subsection{Sample size determination}

The sample size was determined using single population proportion formula considering the following assumptions: $\mathrm{P}=$ $28.9(17)$, significance level $5 \%$ and margin of error $5 \%$. It gives initial sample size of 317 . Since the source population is less than 10,000, (2818), we employed population correction formula for a finite population. Accordingly, the final sample size was calculated to be 286 . By taking into consideration $10 \%$ non-response rate, the final sample size was 315 .

\subsection{Sampling procedure}

Stratified random sampling technique was employed to select study participants. First the students were stratified from grade 9 to 12 and then the sample population was proportionally assigned to each grade. Finally samples were selected from each class by simple random sampling technique using students' roster as a sample frame.

\subsection{Operational definition}

\section{Parents}

biological parents or step parents or foster parents

\section{Parent-adolescent communication on SRH}

Students open discussion on at least two SRH issues (STIs/ HIV/AIDS, condom, sexual intercourse, premarital sex, puberty, menstrual cycle, unwanted pregnancy and contraception) with their parents in the last 12 months initiated by the adolescents or both.

\section{Adolescent}

In this study context participant in the age range of 15-24 years were considered as adolescent

\subsection{Data collection instrument}

Data were collected using pretested, validated, self-administered structured questionnaire which was developed through reviewing different related scientific literatures. The data were collected by six diploma graduate nurses under the supervision of two supervisors and principal investigator. Data collectors were supervised by two diploma midwives.

\subsection{Data quality control}

Data quality was ensured through standardized data collection materials and the English version questionnaire was translated to local language (Oromic) version for appropriateness and easiness by language experts in both cases. The Oromic version was again translated back to English language to verify the content validity of the original version.

Two days of training was given for data collectors about the aim of the study, how to approach the study subjects, sampling procedure and the content of the questionnaire. The questionnaires were pre-tested on $5 \%$ of participants at the Jiren secondary and preparatory school one week ahead of actual data collection and further modified based on the results. Continuous follow-up and supervision were made by the two supervisors and principal investigator and collected data were reviewed and checked daily for clarity, completeness and consistency. 


\subsection{Data entry, processing and analysis}

The collected data was compiled, reviewed, coded and entered in to Epidata version 3.1 and exported to SPSS version 20 for analysis. Data was checked and cleaned for its completeness and errors in coding and entering before analysis. Descriptive statistical analysis was used to compute frequency and a percentage of independent and dependent variables. A logistic regression model was computed to see the association of independent variables and dependent variables. Variables with $p$ $\leq 0.25$ on bivariable logistic regression were considered as candidates for multivariable regression and $P$-values of $<0.05$ were considered to be statistically significant in the multivariable analysis. Crude and adjusted odds ratios with their $95 \%$ confidence intervals were calculated. The Hosmer and Lemeshow goodness-of-fit test were checked and gave a $p$ value of 0.704 , indicating evidence of fitness of the model.

\section{Results}

\subsection{Socio demographic characteristics of the study population}

A total of 315 students were included to the study. The mean age of the respondents was $20.2 \pm 2.6$ years. Regarding religion most of the respondents 263(83.5\%) were muslim. Majority of the respondents were ethnically Oromo, accounting for 259 (82.2\%).One hundred forty one (44.7\%) was grade nine students followed by grade ten students who account 105 (33.3\%). Most of adolescent lives with both parents $279(88.6 \%)$. Almost half $(53.3 \%)$ of the participants had ever got SRH information (Table 1). 
Table 1

:Socio demographic characteristics of Agaro secondary and preparatory school students and their parents, Agaro town, Southwest Ethiopia, 2019.

\begin{tabular}{|c|c|c|c|}
\hline Variables & & Number & Percent \\
\hline \multirow[t]{2}{*}{ Sex } & Male & 150 & 47.6 \\
\hline & Female & 165 & 52.4 \\
\hline \multirow[t]{2}{*}{ Age(years) } & $15-19$ & 142 & 45.1 \\
\hline & $20-24$ & 173 & 54.9 \\
\hline \multirow[t]{4}{*}{ Grades } & 9 & 141 & 44.7 \\
\hline & 10 & 105 & 33.3 \\
\hline & 11 & 49 & 15.6 \\
\hline & 12 & 20 & 6.4 \\
\hline \multirow[t]{3}{*}{ Ethnicity } & Oromo & 263 & 83.5 \\
\hline & Amhara & 29 & 9.2 \\
\hline & Others* & 23 & 7.3 \\
\hline \multirow[t]{2}{*}{ Residence } & urban & 112 & 35.6 \\
\hline & rural & 203 & 64.4 \\
\hline \multirow[t]{2}{*}{ Have boy/girlfriend } & yes & 83 & 26.3 \\
\hline & no & 232 & 73.7 \\
\hline \multirow[t]{2}{*}{ Had ever got SRH information } & yes & 168 & 53.3 \\
\hline & no & 147 & 46.7 \\
\hline \multirow[t]{3}{*}{ Religion } & Muslim & 263 & 83.5 \\
\hline & Orthodox & 31 & 9.8 \\
\hline & Otherst & 21 & 6.7 \\
\hline \multirow[t]{4}{*}{ Living arrangement of adolescents } & With both parents & 279 & 88.6 \\
\hline & With one parent & 17 & 5.4 \\
\hline & With relative & 11 & 3.5 \\
\hline & Alone & 8 & 2.5 \\
\hline \multirow[t]{3}{*}{ Marital status of parents } & Together & 295 & 93.7 \\
\hline & Widowed & 14 & 4.4 \\
\hline & Divorced & 6 & 1.9 \\
\hline \multirow[t]{3}{*}{ Mother's educational status } & Illiterate & 91 & 28.9 \\
\hline & Primary school & 150 & 47.6 \\
\hline & Secondary school and above & 74 & 23.5 \\
\hline Father's educational status & Illiterate & 73 & 23.2 \\
\hline
\end{tabular}




\begin{tabular}{|c|c|c|c|}
\hline \multicolumn{2}{|l|}{ Variables } & \multirow{2}{*}{\begin{tabular}{|l|} 
Number \\
134
\end{tabular}} & \multirow{2}{*}{$\begin{array}{l}\text { Percent } \\
42.5\end{array}$} \\
\hline & primary school & & \\
\hline & secondary school and above & 108 & 34.3 \\
\hline \multirow[t]{5}{*}{ Occupation of family } & House wife & 71 & 22.5 \\
\hline & Farmer & 108 & 34.3 \\
\hline & Employed & 58 & 18.4 \\
\hline & private & 64 & 20.3 \\
\hline & Others & 14 & 4.4 \\
\hline \multirow[t]{2}{*}{ Family size } & $<5$ & 175 & 55.6 \\
\hline & $\geq 5$ & 140 & 44.4 \\
\hline \multirow[t]{4}{*}{ Estimated family income per month (in birr) } & $<1000$ & 34 & 18.9 \\
\hline & $1000-2000$ & 81 & 45 \\
\hline & $\geq 2000$ & 65 & 36.1 \\
\hline & I don't know & 135 & 42.9 \\
\hline *Wolayta, Dawuro, Tigre; tretired,unemployec & & & \\
\hline
\end{tabular}

\subsection{Communication on sexual and reproductive health issues}

Although $92 \%$ of the respondents reported that it was important to discuss sexual and reproductive health issues with parents, only $61.3 \%$ had communicated with their parents on at least two SRH topics. The major topics discussed among participants were premarital sex (40\%) followed puberty (37.8\%) (Table 2). 
Table 2

; Different SRH issues discussed by secondary and preparatory school students in Agaro town, Southwest Ethiopia,2019

\begin{tabular}{|c|c|c|c|c|}
\hline SRH issues discussed & Category & Male $(n, \%)$ & Female(n,\%) & Total $(n, \%)$ \\
\hline \multirow[t]{3}{*}{ Important to discuss on SRH issues } & agree & $130(86.7)$ & $160(97)$ & 290(92) \\
\hline & neutral & $6(4)$ & 2 & 2.5 \\
\hline & disagree & $14(9)$ & 3 & 5.5 \\
\hline \multirow[t]{2}{*}{ Discussion on at least two SRH issues } & yes & $101(67.3)$ & $92(55.7)$ & 193(61.3) \\
\hline & no & $49(32.7)$ & $73(44.3)$ & $122(38.7)$ \\
\hline \multirow[t]{2}{*}{ Contraceptive } & yes & $24(16)$ & $38(23)$ & 62(19.7) \\
\hline & no & 126(84) & $127(77)$ & $253(80.3)$ \\
\hline \multirow[t]{2}{*}{ Menstrual cycle } & yes & $21(14)$ & $46(27.9)$ & $67(21.3)$ \\
\hline & no & $129(86)$ & $119(72.1)$ & 248(78.7) \\
\hline \multirow[t]{2}{*}{ STIS/HIV/AIDS } & yes & $45(30)$ & $67(40)$ & $112(35.6)$ \\
\hline & no & $105(70)$ & $98(60)$ & $203(64.4)$ \\
\hline \multirow[t]{2}{*}{ Unwanted pregnancy } & yes & $24(16)$ & $51(30.9)$ & $75(23.8)$ \\
\hline & no & $126(84)$ & $114(69.1)$ & $240(76.2)$ \\
\hline \multirow[t]{2}{*}{ premarital sex } & yes & $39(26)$ & $87(52.3)$ & $126(40)$ \\
\hline & no & $111(74)$ & $78(47.3)$ & $189(60)$ \\
\hline \multirow[t]{2}{*}{ Abortion } & yes & $12(8)$ & 17(10.3) & $29(9.3)$ \\
\hline & no & 138(92) & $148(89.7)$ & $286(90.7)$ \\
\hline \multirow[t]{2}{*}{ Puberty } & yes & 65(43.3) & $54(32.7)$ & 119(37.8) \\
\hline & no & $85(56.7)$ & $111(67.3)$ & $196(62.2)$ \\
\hline \multirow[t]{2}{*}{ Sexual intercourse } & yes & $27(18)$ & 18(10.9) & $45(14.3)$ \\
\hline & no & 123(82) & $147(89.1)$ & $270(85.7)$ \\
\hline \multirow[t]{2}{*}{ Condom } & yes & $21(14)$ & $15(9.1)$ & $36(11.4)$ \\
\hline & no & $129(86)$ & $150(90.9)$ & $279(88.6)$ \\
\hline
\end{tabular}

Only hundred twelve (35.6\%) of the students had discussed about STIs/HIV/AIDS because of parents' lack of knowledge (49.5\%) and shame (35.9\%). Similarly only $23.8 \%$ of the students discussed with their parents about unwanted pregnancy due to shame( $46 \%)$ and parents lack of $(24.8 \%)$ (Table 3$)$.

Table 3; Reasons for adolescent high school students for not discussing on SRH issues with their parents in Agaro town, Southwest Ethiopia, 2019 


\begin{tabular}{|c|c|c|c|c|c|c|c|}
\hline \multirow{2}{*}{$\begin{array}{l}\text { Topic of } \\
\text { discussion }\end{array}$} & \multirow{2}{*}{$\begin{array}{l}\text { Not } \\
\text { discussed } \\
(n, \%)\end{array}$} & \multicolumn{6}{|c|}{ Reasons for not discussing } \\
\hline & & Shame* & $\begin{array}{l}\text { Culturally } \\
\text { unacceptable* }\end{array}$ & $\begin{array}{l}\text { Parents lack } \\
\text { knowledge* }\end{array}$ & $\begin{array}{l}\text { Parents } \\
\text { too busy* }\end{array}$ & $\begin{array}{l}\text { Difficult and } \\
\text { embar-rassing } \\
\star\end{array}$ & Otherst \\
\hline Contraceptive & $253(80.3)$ & $129(40.9)$ & $84(26.7)$ & $95(30.2)$ & $46(14.6)$ & $54(17.1)$ & $8(2.5)$ \\
\hline STIS/HIV/AIDS & $203(64.4)$ & 113(35.9) & $76(24.1)$ & $156(49.5)$ & $37(11.7)$ & $31(9.8)$ & 11(3.4) \\
\hline $\begin{array}{l}\text { Unwanted } \\
\text { pregnancy }\end{array}$ & $240(76.2)$ & $145(46)$ & $32(10.2)$ & $78(24.8)$ & $27(8.5)$ & $64(20.3)$ & $7(2.2)$ \\
\hline Premarital sex & $189(60)$ & $178(56.5)$ & $57(18.1)$ & $41(13)$ & $19(6)$ & $94(29.8)$ & $13(4.1)$ \\
\hline $\begin{array}{l}\text { Sexual } \\
\text { intercourse }\end{array}$ & $270(85.7)$ & $190(60.3)$ & $31(9.8)$ & $51(16.2)$ & 12(3.8) & $75(23.8)$ & $15(4.8)$ \\
\hline Condom & $279(88.6)$ & $201(63.8)$ & $74(23.5)$ & $25(7.9)$ & $13(4.1)$ & $87(27.6)$ & 11(3.5) \\
\hline Puberty & $196(62.2)$ & $82(26)$ & $11(3.5)$ & $32(10.2)$ & $43(13.7)$ & $18(5.7)$ & $7(2.2)$ \\
\hline
\end{tabular}

*multiple responses were possible, † Belief that it initiate sex, religious belief, don't now

\subsection{Factors associated with parent-adolescent communications on SRH issues}

Bivariable logistic regression analysis was performed to assess association between each independent variable and outcome variable. Results of bivariable analysis showed that sex of student, mother education status, father education status, age, having ever got SRH information, having boy/girlfriend, residence, occupation of family and family size show association with parent adolescent communication. All of them were entered to multivariable analysis to control effect of confounding. The result of multivariable logistic regression model revealed that educational status of biological parents, family size of $<5$ and having boy/girlfriend were significantly associated with parent adolescent communication.

The odds of parent-adolescent communication were 6.4 times [AOR $=6.41 .6 ; 95 \% \mathrm{Cl}$ : 3.36,12.37] higher among students of family size of $<5$ than their counter parts. The odds of parent-adolescent communication were 1.99 times [AOR $=1.99 ; 95 \%$ $\mathrm{Cl}: 1.3,8]$ higher among students who had boy/girlfriend than those who had no boy/girlfriend.

Adolescents, whose mothers had primary education, were 3.67 times more likely to communicate on SRH issues with their parents than those students whose mothers were illiterate (AOR $=3.67 ; 95 \% \mathrm{Cl}$ : 1.93-6.97). Similarly, adolescents, whose mothers had secondary education were 2.86 times more likely to communicate on SRH issues with their parents than those students whose mothers were illiterate ( $\mathrm{AOR}=2.8695 \% \mathrm{Cl}: 1.2,6.8)$. This study also revealed fathers' education [primary education $(A O R=5.895 \% \mathrm{Cl}: 2.8,12.3)$, secondary education $(\mathrm{AOR}=3.2195 \% \mathrm{Cl}: 1.55,6.59)]$ were significantly associated with parent adolescent communication after controlling for confounders(Table 4). 
Table 4

; Bivariate and multivariable binary logistic regression analysis for factors associated with parent-adolescent communication among high school and preparatory school students in Agaro town, Southwest Ethiopia 2019.

\begin{tabular}{|c|c|c|c|c|c|c|c|}
\hline \multirow[t]{2}{*}{ Variables } & \multirow[t]{2}{*}{ Category } & \multicolumn{2}{|c|}{$\begin{array}{l}\text { Parent- } \\
\text { adolescent } \\
\text { communication }\end{array}$} & \multicolumn{2}{|c|}{ Bivariable Analysis } & \multicolumn{2}{|c|}{ Multivariable analysis } \\
\hline & & Yes & No & $\begin{array}{l}\mathrm{P} \text { - } \\
\text { value }\end{array}$ & COR $(95 \% \mathrm{Cl})$ & P-value & AOR $(95 \% \mathrm{Cl})$ \\
\hline \multirow[t]{2}{*}{ Age(years) } & $15-19$ & 82 & 60 & 1 & 1 & 1 & \\
\hline & $20-24$ & 111 & 62 & .245 & $1.31[.83,2.1]$ & .911 & $1[.58,1.81]$ \\
\hline \multirow[t]{3}{*}{ Mother educational level } & Illiterate & 36 & 55 & 1 & 1 & 1 & 1 \\
\hline & primary & 109 & 41 & 0 & $4[2.3,7]$ & $\leq 0.001$ & $3.67[1.93,6.97]$ \\
\hline & secondary & 48 & 26 & .001 & $2.8[1.49,5.33]$ & $0.017^{\star}$ & $2.86[1.2,6.8]$ \\
\hline \multirow[t]{3}{*}{ Father educational status } & illiterate & 28 & 45 & 1 & 1 & 1 & 1 \\
\hline & primary & 96 & 38 & $\leq .001$ & $4[2.2,7.4]$ & $\leq .001 *$ & $5.8[2.8,12.3]$ \\
\hline & secondary & 69 & 39 & .001 & $2.8[1.54,5.25]$ & $0.002^{\star}$ & $3.2[1.55,6.59]$ \\
\hline \multirow[t]{5}{*}{ Occupation of family } & Housewife & 40 & 31 & 1 & 1 & 1 & 1 \\
\hline & farmer & 61 & 47 & .985 & $1[.55,1.84]$ & .613 & $1.2[.58,2.45]$ \\
\hline & employed & 37 & 21 & .391 & $1.36[.67,2.78]$ & .676 & $1.19[.52,2.73]$ \\
\hline & $\begin{array}{l}\text { Private } \\
\text { worker }\end{array}$ & 45 & 19 & .095 & $1.83[.9,3.74]$ & .108 & $2[.85,4.77]$ \\
\hline & othert & 10 & 4 & .300 & $1.93[.55,6.76]$ & .955 & $1[.25,4.3]$ \\
\hline \multirow[t]{2}{*}{ Sex } & male & 101 & 49 & .036 & $1.636[1,2.58]$ & .100 & $2.45[.84,6.89]$ \\
\hline & female & 92 & 73 & 1 & 1 & 1 & 1 \\
\hline \multirow[t]{2}{*}{ Residence } & rural & 115 & 88 & 1 & 1 & 1 & 1 \\
\hline & urban & 78 & 34 & 0.024 & $1.75[1,2.86]$ & .774 & $.86[.32,2.34]$ \\
\hline \multirow[t]{2}{*}{ Family size } & $<5$ & 129 & 46 & $\leq .001$ & $3.3[2,5.34]$ & $\leq .001 *$ & $6.4[3.36,12.37]$ \\
\hline & $\geq 5$ & 64 & 76 & 1 & 1 & 1 & 1 \\
\hline \multirow[t]{2}{*}{ Has boy/girlfriend } & yes & 59 & 24 & .034 & $1.79[1,3]$ & $.041^{\star}$ & $1.99[1,3.8]$ \\
\hline & no & 134 & 98 & 1 & 1 & 1 & 1 \\
\hline \multirow{2}{*}{$\begin{array}{l}\text { Had ever got SRH } \\
\text { information }\end{array}$} & yes & 110 & 58 & .102 & $.68[.43,1]$ & .260 & $.73[.43,1.26]$ \\
\hline & no & 83 & 64 & 1 & 1 & 1 & 1 \\
\hline
\end{tabular}

\section{Discussion}

This study has attempted to assess the prevalence of parent- adolescent communication on SRH issues and its associated factors in Agaro secondary and preparatory school students, Southwest Ethiopia. Although the majority (92\%) of participants 
reported that, it is important to discuss on SRH issues with their parents, only $61.3 \%$ (193) [95\% Cl: 55.6,66.7] were discussed about SRH issues with their parents. This finding was in line with two independent studies done in Ethiopia, 59.1\% in Yergalem, South Ethiopia (18)and 57.6\% in Mekelle, Northern Ethiopia (19). However, this result was higher than a study done in Dabat, Northwest Ethiopia ,Robe, Southeast Ethiopia, Dire Dewa, Eastern Ethiopia and India which reported 48.5\%,47\%,37\% and $29 \%$ respectively $(14,20-22)$. This difference might be due to the difference in socio-demographic, cultural difference and accessing sexual reproductive health information. For example, the possible explanation of higher prevalence in our study could be due to home to home, school and mass health education and information by Jimma University health science students during community based team training program every year.

In contrast, the finding of the current study is lower than that of a study conducted in Hayik, Northeast Ethiopia 83\%(23), Malawi $74 \%(24)$ and Ghana $82.3 \%(25)$. The difference might be related to difference in sample size used, socio-demographic status, level of awareness, culture related to openness related to SRH issues and the difference in accessing SRH

information. For instance, study in Hayik, Northeast Ethiopia in which three quarter of participants resides in urban area who has adequate access to reproductive health services.

Regarding challenges for not discussing SRH issues shame, cultural taboos, embarrassments and parents' lack of knowledge were mentioned by the majority of participants. For instance, $76.2 \%$ of participants were not discussed regarding unwanted pregnancy due to shame and parents' lack of knowledge $46 \%$ and $24.8 \%$ respectively. This was consistent with previous studies $(23,26)$. This might be due to the fact that sexual conversations are deemed a taboo subject in many African communities, including our country.

In agreement with earlier studies, in this study educational status of father and mother showed statistical significance with parent adolescent communication about SRH issues $(23,27,28)$. This could be due to educated parents have better access to health service information, improved perceptions of SRH issue and better skill of communication.

In the same manner, the study showed that those students whose family size was less than five were more likely to communicate compared to those whose family size was $\geq 5$. This result agreed with previous study (29). This result demonstrated that those parents with small family size had better chance of discussing SRH issues with their children. Finally, the present study revealed that there were significant association between parent adolescent's sexual and reproductive issues and having boy/girlfriend. The possible reason for this association might be students who enter to relationship may raise about SRH issues with each other and they may discuss with their parents for more information.

\section{Limitation Of The Study}

1 st due to cross-sectional nature of the study, it was difficult to imply cause-effect relationship. 2nd this study was done to assess parent adolescent communication were based on adolescents' perceptions, which may not reflect what parents were actually doing. 3rd, since it was based on self-reporting, it might be affected by social desirability bias because of sensitive nature and cultural barrier for open discussion and finally additional qualitative study should be done to explore more on adolescents and parents communication.

\section{Conclusion}

This study showed about two third of adolescents had discussion on sexual and reproductive health issues with their parents on at least two sexual and reproductive health issues. Educational level of parents, having family size of $<5$ and having boy/girlfriend were significantly associated with communication. The main reasons for not communicated was cultural taboos, shame and parents lack of knowledge.

\section{Abbreviations}

AIDS

Page $11 / 14$ 
Acquired immune deficiency syndrome

$\mathrm{SRH}$

Sexual reproductive health

STIS

Sexually transmitted infections

HIV

Human immune virus

\section{Declarations}

\section{Financial support}

Nil.

\section{Conflicts of Interest}

The authors of this study declare that have no competing interests

\section{Ethical approval}

Ethical clearance was obtained from the Institutional Review Board of the Jimma University. A formal letter of cooperation was written to the school administration Agaro District Education Office for permission and support.

\section{Consent to participate}

After ethical approval, the objective of the study was described and oral informed consent was obtained from study participants aged $\geq 18$ years and parental informed consent was obtained for those who were aged $\geq 15$ years after explaining the purpose of the study. Information was recorded anonymously and confidentiality and beneficence were assured throughout the process.

\section{Consent for publication}

Not applicable

\section{Data Availability}

The data used to support the findings of this study are available from the corresponding author

upon reasonable request.

\section{Author Contributions}

Both authors made substantial contributions to conception and acquisition of data, or analysis and interpretation of data; took part in drafting the article or revising it critically for important intellectual content; agreed to submit to the current journal; gave final approval of the version to be published and agree to be accountable for all aspects of the work.

\section{Acknowledgement}

We want to acknowledge our study participants and data collectors.

\section{References}


1. United Nations Children's Fund (UNICEF). Progress for Children: A report card on adolescents. Number 10. ERIC Clearinghouse; 2012.

2. Richter LM. Studying adolescence. Science. 2006 Jun;30(5782):1902-5. 312(.

3. Braine T. Adolescent pregnancy: a culturally complex issue. World Health Organization. Bulletin of the World Health Organization. 2009 Jun 1;87(6):410.

4. Lewis DA. HIV/sexually transmitted infection epidemiology, management and control in the IUSTI Africa region: focus on sub-Saharan Africa. Sexually transmitted infections. 2011 Dec 1;87(Suppl 2):ii10-3.

5. Singh NS, Aryasinghe S, Smith J, Khosla R, Say L, Blanchet K. A long way to go: a systematic review to assess the utilisation of sexual and reproductive health services during humanitarian crises. BMJ global health. 2018 May 1;3(2).

6. Yang H, Stanton B, Li X, Cottrel L, Galbraith J, Kaljee L. Dynamic association between parental monitoring and communication and adolescent risk involvement among African-American adolescents. J Natl Med Assoc. 2007 May;99(5):517.

7. Jerman P, Constantine NA. Demographic and psychological predictors of parent-adolescent communication about sex: A representative statewide analysis. Journal of youth and adolescence. 2010 Oct 1;39(10):1164-74.

8. Clawson CL, Reese-Weber M. The amount and timing of parent-adolescent sexual communication as predictors of late adolescent sexual risk-taking behaviors. Journal of Sex Research. 2003 Aug 1;40(3):256 - 65.

9. Ayehu A, Kassaw T, Hailu G. Young people's parental discussion about sexual and reproductive health issues and its associated factors in Awabel woreda, Northwest Ethiopia. Reproductive health. 2016 Dec 1;13(1):19.

10. Team YA. Assessment of youth reproductive health programs in Ethiopia. Link: https://bit. ly/3cKrfcj. 2004 Apr.

11. Federal Democratic Republic of Ethiopia(FDROE). Ministry of Health (MOH). National Reproductive Health Strategy (2007-2015)

https://extranet.who.int/countryplanningcycles/sites/default/files/planning_cycle_repository/ethiopia/ayrh_strategy.pdf.

12. Federal Democratic Republic of Ethiopia Minstry of Health. (2006) National adolescent and youth reproductive health strategy2006-2015.

http://wwwcorhaethiopiaorg/docs/AYRH/National\%2520Adolescent\%2520and\%2520Youth\%2520Reprod.

13. Tesso DW, Fantahun MA, Enquselassie F. Parent-young people communication about sexual and reproductive health in E/Wollega zone, West Ethiopia: Implications for interventions. Reproductive health. 2012 Dec 1;9(1):13.

14. Ayalew M, Mengistie B, Semahegn A. Adolescent-parent communication on sexual and reproductive health issues among high school students in Dire Dawa, Eastern Ethiopia: a cross sectional study. Reproductive health. 2014 Dec;11(1):1-8.

15. Melaku YA, Berhane Y, Kinsman J, Reda HL. Sexual and reproductive health communication and awareness of contraceptive methods among secondary school female students, northern Ethiopia: a cross-sectional study. BMC public health. $2014 \operatorname{Dec}$ 1;14(1):252.

16. Yadeta TA, Bedane HK, Tura AK. Factors affecting parent-adolescent discussion on reproductive health issues in Harar, Eastern Ethiopia: a cross-sectional study. Journal of environmental and public health. 2014 May 29;2014.

17. Shewasinad S, Alelign Z, Yeshitla K, Bunga G, Negash S. Assessment of Communication on Sexual and Reproductive Health Issues among Mizan Secondary and Preparatory School Students with Parents, Mizan Town, Ethiopia, 2016. American Journal of Health Research. 2017 Sep 7;5(5):131 - 40.

18. Yohannes Z, Tsegaye B. Barriers of parent-adolescent communication on sexual and reproductive health issues among secondary and preparatory school students in Yirgalem, Town, South Ethiopia. Fam Med Med Sci Res. 2015;4(181):2.

19. Yowhanes Z, Berhe H, Hailu D. Assessment of parent-adolescent communication about sexual and reproductive health among high school students in mekelle town, Northern Ethiopia. Global Journal of Medical Research. 2016;16:2-E.

20. Dagnachew Adam N, Demissie GD, Gelagay AA. Parent-Adolescent Communication on Sexual and Reproductive Health Issues and Associated Factors among Preparatory and Secondary School Students of Dabat Town, Northwest Ethiopia.

Page $13 / 14$ 
Journal of Environmental and Public Health. 2020 Jul 25;2020.

21. Habte NM, Melku AT, Alemayehu MT. Parent-adolescent Communication On Sexual and Reproductive Health Matters and Associated Factors Among Secondary and Preparatory School Students in Robe Town, Bale Zone, Southeast Ethiopia, 2017. Journal of Public Health International. 2019 Jul;9(4):1. 1(.

22. Widman L, Choukas-Bradley S, Helms SW, Golin CE, Prinstein MJ. Sexual communication between early adolescents and their dating partners, parents, and best friends. The Journal of Sex Research. 2014 Oct 1;51(7):731 - 41.

23. Chane T, Cherie N. Parent-adolescent communication about sexual and reproductive health and associated factors among preparatory school students in Haiyk Town, North East Ethiopia. Res Med Eng Sci. 2018;5(2):417-23.

24. Akim J. Parents' attitudes to adolescent sexual behaviour in Lesotho. Population and Poverty Studies Programme. 2001.

25. Manu AA, Mba CJ, Asare GQ, Odoi-Agyarko K, Asante RK. Parent-child communication about sexual and reproductive health: evidence from the Brong Ahafo region, Ghana. Reproductive Health. 2015 Dec 1;12(1):16.

26. Adu-Mireku S. Family communication about HIV/AIDS and sexual behaviour among senior secondary school students in Accra, Ghana. African Health Sciences. 2003;3(1):7-14.

27. Musa OI, Akande TM, Salaudeen AG, Soladoye OM. Family communication on HIV/AIDS among secondary school students in a northern state of Nigeria. African Journal of Infectious Diseases. 2008 Sep 23;2(1):46-50.

28. Fanta M, Lemma S, Sagaro GG, Meskele M. Factors associated with adolescent-parent communication of reproductive health issues among high school and preparatory students in Boditi town, Southern Ethiopia: a cross-sectional study. Patient Intelligence. 2016 Oct 14;8:57-70.

29. Mekie M, Taklual W, Melkie A, Addisu D. Parental communication on sexual and reproductive health issues and its associated factors among preparatory school students in Debre Tabor, Northcentral Ethiopia: institution based crosssectional study. BMC research notes. 2019 Dec 1;12(1):598. 